\title{
Sugar-Rich Foods Carry Osmotolerant Yeasts with Intracellular Helicobacter Pylori and Staphylococcus spp
}

CrossMark

\author{
Farideh Siavoshi ${ }^{1, *}$, Marzieh Sahraee ${ }^{1}$, Samira Heydari ${ }^{1}$, Abdolfattah Sarrafnejad ${ }^{2}$, Parastoo Saniee ${ }^{3}$, \\ Atefeh Tavakolian ${ }^{3}$, Sheida Heidarian ${ }^{1}$
}

1. Department of Microbiology, School of Biology, University College of Sciences, University of Tehran, Tehran, Iran

2. Department of Immunology, School of Public Health, Tehran University of Medical Sciences, Tehran, Iran

3. Department of Microbiology and Microbial Biotechnology, Faculty of Life Science and Biotechnology, Shahid Beheshti University G.C, Tehran, Iran

\section{* Corresponding Author:}

Farideh Siavoshi, Ph.D Department of Microbiology, School of Biology, University College of Sciences, University of Tehran, Enghelab Avenue, Tehran 14176-14411, Iran.

Tel: + 982161112460

Fax: +982166492992

Email: siavoshi@khayam.ut.ac.ir

Received: 15 Jan. 2020

Accepted: 06 Jun. 2020

\section{ABSTRACT}

\section{BACKGROUND}

Sugar-rich foods are of the main components of daily human meals. These foods with high sugar and low water content kill bacteria. However, osmotolerant yeasts survive and multiply. The aim of this study was to examine the occurrence of intracellular Helicobacter pylori (H. pylori) and Staphylococcus spp. in yeast isolates from sugar-rich foods.

\section{METHODS}

Thirty-two yeast isolates from fresh fruits, dried fruits, commercial foods, and miscellaneous foods were identified by the sequencing of amplified products of 26S rDNA. Fluorescence microscopy and LIVE/DEAD bacterial viability kit were used to examine the occurrence of live bacteria inside the yeast's vacuole. Immunofluorescence assay was used to confirm the identity of intracellular bacteria as H. pylori and Staphylococcus. Polymerase chain reaction (PCR) was used for the detection of 16S rDNA of H. pylori and Staphylococcus in the total DNA of yeasts.

\section{RESULTS}

Yeasts were identified as members of seven genera; Candida, Saccharomyces, Zygosaccharomyces, Pichia, Meyerozyma, Metschnikowia, and Wickerhamomyces. Intravacuolar bacteria were stained green with a bacterial viability kit, revealing that they were alive. Immunofluorescence assay confirmed the identity of intracellular H. pylori and Staphylococcus spp. PCR results revealed that among the 32 isolated yeasts, 53\% were $H$. pylori-positive, $6 \%$ were Staphylococcus-positive, $18.7 \%$ were positive for both, and $21.8 \%$ were negative for both.

\section{CONCLUSION}

Detection of H. pylori- and Staphylococcus-16S rDNA in yeast isolates from dried fruits, and commercial foods showed the occurrence of more than one kind of endosymbiotic bacterium in yeasts' vacuoles. While the establishment of H. pylori and Staphylococcus in yeast is a sophisticated survival strategy, yeast serves as a potent bacterial reservoir.

\section{KEYWORDS:}

Sugar-rich foods, Yeast, Intracellular bacteria, Helicobacter pylori, Staphylococcus spp

\section{Please cite this paper as:}

Siavoshi F, Sahraee M, Heydari S, Sarrafnejad AF, Saniee P, Tavakolian A, Heidarian S. Sugar-Rich Foods Carry Osmotolerant Yeasts with Intracellular Helicobacter Pylori and Staphylococcus spp. Middle East J Dig Dis 2020;12:182-193. doi: 10.34172/mejdd.2020.181.

\section{INTRODUCTION}

The gastrointestinal tract is the main portal of entry into the human body for food- and water-borne microorganisms. Helicobacter pylori (H. pylori) is a bacterium involved in peptic diseases with unknown environmental sources and route of transmission. ${ }^{1}$ On the one hand, close contact is believed to be the 
main route of transmission of $H$. pylori, which occurs from mother to child and among siblings. ${ }^{2}$ On the other hand, H. pylori is considered as a gastric colonizer whose entry into the human stomach may occur along with the ingestion of food and water. ${ }^{3}$ However, there is no convincing evidence to indicate the survival of $H$. pylori in food ${ }^{4}$ and water. ${ }^{5}$ It has been suggested that food processing steps exert physical and chemical stresses on H. pylori, and thus different foods cannot be considered as vehicles for carrying $H$. pylori to the human gastrointestinal tract. ${ }^{6}$ Furthermore, several reports demonstrated that $H$. pylori inside foodborne yeast could be protected from stressful conditions present in different food materials. ${ }^{7}$ On the other hand, Staphylococcus spp. are typically found in both fermented and non-fermented animal and plant foods. ${ }^{8}$ The coexistence of Staphylococcus and yeast has been frequently reported, for example, in food and microbial biofilms. ${ }^{9}$ A clinically significant yet not fully elucidated fungal-bacterial interaction is the one occurring between Candida albicans and Staphylococcus spp. ${ }^{10}$

Yeasts are ubiquitous unicellular fungi that live as saprophytes on plant or animal materials, preferentially using sugars as carbon and energy sources. ${ }^{11}$ Yeasts are equipped with different hydrolytic enzymes, such as glycosidases, cellulases, proteinases, and lipases, ${ }^{11-13}$ which enable them to use different kinds of substrates and thus thrive in a wide range of environmental niches. Reports indicate that compared with bacteria, yeasts are more tolerant of stressful conditions such as acidic $\mathrm{pH}$ and are also able to grow in a wider range of water activity. ${ }^{14}$

Sugar-rich foods with low water activity are considered to be stressful materials that are hostile to microbial life, causing bacterial death due to osmotic shock. ${ }^{15}$ However, osmotolerant yeasts not only tolerate the osmotic shock but are capable of growing under such conditions. It has been demonstrated that osmotolerant yeasts accumulate glycerol or other polyols in response to low water activity, maintaining or restoring an inside-directed driving force for water across their cell membrane. ${ }^{11}$ Moreover, these polyols, with their hydroxyl groups, retain intracellular polymers in hydrated form, thus preserving enzyme activity. ${ }^{16-18}$ Yeasts that tolerate environments with highsugar and low-water contents are osmotolerant yeasts encompassing most of the ascomycetes. ${ }^{19}$ Fresh fruits with high levels of sugars and other nutrients and intermediate (15-50\%) water content provide favorable conditions for microbial growth. ${ }^{20}$ However, bacteria cannot tolerate the acidic $\mathrm{pH}$ of these fruits and are thus eliminated, allowing osmotolerant yeasts to multiply and become established as the normal microflora in the sweet niche of fruits. ${ }^{21}$ Dried fruits, preserved fruits, and fruit syrups are also sugar-rich foods with low water activity that carry osmotolerant yeasts as their normal microflora. ${ }^{14}$ Different kinds of sugars that are used as additives in sweet foods might also carry osmotolerant yeasts. These yeasts are common contaminants of sugar factories and those that process concentrated solutions of sugars. ${ }^{22}$ Sugars are produced from molasses of sugar beet or sugar cane that have high microbial contents, mainly consisting of bacterial spores, yeasts, and molds. Yeasts and molds do not usually survive the main steps of sugar manufacturing operations, which involve high temperatures and reduced water activity. However, airborne yeasts or those that occur on the surface of refinery equipment can recontaminate the raw sugar in the final steps, multiply, and increase their population to 104-106 per gram of sugar. ${ }^{23}$ Accordingly, most of the yeast populations in sugar products are postproduction contaminants. ${ }^{24}$

In this study, yeast isolates from sugar-rich foods, fresh fruits, dried fruits, commercial unprocessed and processed sweet foods, and miscellaneous foods were examined for the occurrence of intracellular $H$. pylori and Staphylococcus spp. by molecular and microscopic methods. Specific primers were used for the detection of H. pylori and Staphylococcal 16S rDNA in the total DNA of yeasts. Light and fluorescence microscopes were used for observing the live and moving bacteria inside the yeasts. Moreover, FITC (Fluorescein isothiocyanate) conjugated antibodies were used for immunodetection of H. pylori and Staphylococcus spp. inside the vacuole of yeast cells. The rationale of the study was to demonstrate that yeasts in popular sugar-rich foods may serve as reservoirs of $H$. pylori and Staphylococcus, facilitating their spread within human populations.

\section{MATERIALS AND METHODS}

\section{Collection and culture of samples}

Sixty samples were collected from high-sugar foods 
and classified into four groups: fresh fruits $(\times 15)$ : blackberry, apple, grape, persimmon, peach, fig, banana, white dragon, red dragon, Saturn peach, strawberry, carrot, plum, and cantaloupe; dried fruits $(\times 15)$ : whole date, heart of palm, date cube, raisin, and dried apricot; processed and unprocessed commercial foods $(\times 22)$ : brown sugar, icing sugar, quince jam, date syrup, sugarcane syrup, sugarcane foam, cooked beets, kombucha tea, white sugar, sugar cube, cinnamon-flavored sugar cube, low-calorie sweetener, Gaz (traditional Persian sweet), rock candy, black grape syrup, white grape syrup, plain biscuit, and Iranian delight; miscellaneous foods $(\times 8)$ : pistachio, almond, cashew nut, walnut, old pickled garlic, and old pickled garlic syrup. One gram of each food material was inoculated into $3 \mathrm{~mL}$ of brain heart infusion (BHI) broth (Merck, Germany) and incubated at $30^{\circ} \mathrm{C}$ for 7-10 days. A 50$\mu \mathrm{L}$ volume of each BHI broth was surface inoculated on YGC $(0.5 \%$ yeast extract, $2 \%$ glucose, $0.01 \%$ chloramphenicol, and $1.5 \%$ agar) and observed for the growth of yeast after $24-48$ hours of incubation at $30^{\circ} \mathrm{C}$.

\section{Isolation of yeasts}

A single colony was selected from each of the 32 yeast-positive cultures and sub-cultured more than 10 times on YGC agar to ensure the absence of bacterial contamination. Fresh cultures of yeasts were used for gram staining and observation of the typical morphology of yeasts by light microscopy.

PCR-restriction fragment length polymorphism (RFLP) of the internal transcribed spacer (ITS) region in 5.8S rDNA

Fresh cultures of yeasts were used for the extraction of DNA. ${ }^{25}$ The primer pair used to amplify the ITS region was ITS-1 (5'-TCCGTAGGTGAACCTGCGG-3') and ITS-4 (5'-TCCTCCGCTTATTGATATGC-3'). ${ }^{26}$ Amplification was performed with yeast DNA as a template and initial denaturation at $94^{\circ} \mathrm{C}$ for $5 \mathrm{~min}$, followed by 35 cycles of denaturation at $94^{\circ} \mathrm{C}$ for $1 \mathrm{~min}$, annealing at $55^{\circ} \mathrm{C}$ for $1 \mathrm{~min}$, and extension at $72^{\circ} \mathrm{C}$ for $2 \mathrm{~min}$, and a final extension at $72^{\circ} \mathrm{C}$ for $10 \mathrm{~min}$. PCR products were electrophoresed using 1\% agarose gel in Tris-borateEDTA (TBE) buffer $(0.5 \mathrm{x})$ and digested without further purification, using restriction endonucleases HhaI (Promega, USA), HaeIII and HinfI (Bioron, Germany).
Restriction fragments were electrophoresed using 2\% agarose, and the size of fragments was determined according to a 50-1500 bp molecular ladder. Yeasts were classified into 13 groups according to their RFLP pattern. ${ }^{26}$

\section{Amplification and sequencing of 26S rDNA}

Amplification of the D1/D2 region of 26S rDNA of the 32 yeasts was carried out using primers NL1 (5'-GCATATCAATAAGCGGAGGAAAAG-3') and NL4 (5'-GGTCCGTGTTTCAAGACGG-3'). ${ }^{27}$ PCR was performed with initial denaturation at $94^{\circ} \mathrm{C}$ for 1 min followed by 35 cycles of denaturation at $94^{\circ} \mathrm{C}$ for 1 min, annealing at $50^{\circ} \mathrm{C}$ for $1 \mathrm{~min}$, and extension at $72^{\circ} \mathrm{C}$ for $2 \mathrm{~min}$ with final extension at $72^{\circ} \mathrm{C}$ for $5 \mathrm{~min}$. After electrophoresis, PCR products of representatives of the 13 RFLP groups with a size of $600 \mathrm{bp}$ were purified, sequenced, and matched with published sequences in GenBank by using the BLAST program (https://blast. ncbi.nlm.nih.gov).

Light and fluorescence microscopy for observation of intracellular bacteria

Wet mounts were prepared from fresh cultures of the 32 yeasts on YGC agar and examined by light microscopy to observe the moving bacteria inside the vacuoles of yeasts. Furthermore, to find out whether bacteria were alive, a fresh culture of a yeast isolate was used for staining with the LIVE/DEAD BacLight Bacterial Viability Kit (L-7012; Molecular Probes, USA) according to the manufacturer's instructions. A wet mount was examined by a fluorescence microscope (Olympus, Tokyo, Japan), and photographs were taken at different time intervals.

Detection of $\boldsymbol{H}$. pylori-specific 16S rDNA in yeasts

Total DNA from 32 yeast isolates was examined for the presence of $H$. pylori-specific 16S rDNA. PCR was carried out using primers HP1: 5'-GCAATCAGCGTCAGTAATGTTC-3' and HP2: 5'-GCTAAGAGATCAGCCTATGTCC- $3{ }^{\prime}{ }^{28}$ A clinical isolate of $\mathrm{H}$. pylori that was previously identified by amplification and sequencing of $H$. pylori-specific $16 \mathrm{~S}$ rDNA was used as a positive control. PCR reaction mixture without template was used as a negative control. PCR was started with $94^{\circ} \mathrm{C}$ for $3 \mathrm{~min}$ and 33 cycles of $94^{\circ} \mathrm{C}$ for $45 \mathrm{~s}, 57^{\circ} \mathrm{C}$ for 
$1 \mathrm{~min}$ and $72^{\circ} \mathrm{C}$ for $1 \mathrm{~min}$, followed by $72^{\circ} \mathrm{C}$ for $5 \mathrm{~min}$. PCR products were electrophoresed using $1 \%$ agarose gel, and their size was determined using a 50-1500 bp DNA ladder.

\section{Detection of Staphylococcus-specific 16S rDNA in} yeasts

Amplification of Staphylococcus-specific 16S rDNA was performed using the primers 16S-F 5-AACTCTGTTATTAGGGAAGAACA-3, ${ }^{29}$ and 16S-R 5'-CCACCTTCCTCCGGTTTGTCACC-3. ${ }^{30}$ The PCR program consisted of an initial denaturation step at $94^{\circ} \mathrm{C}$ for $10 \mathrm{~min}$, followed by 35 cycles of denaturation at $94^{\circ} \mathrm{C}$ for $45 \mathrm{~s}$, annealing at $54^{\circ} \mathrm{C}$ for $45 \mathrm{~s}$ and extension at $72^{\circ} \mathrm{C}$ for $75 \mathrm{~s}$, and a final extension step for $10 \mathrm{~min}$ at $72^{\circ} \mathrm{C}$. A clinical isolate of Staphylococcus aureus, which was previously identified by amplification and sequencing of Staphylococcus-specific 16S rDNA, was used as a positive control. PCR reaction mixture without template was used as a negative control. The size of PCR product was determined as above. The PCR product amplified from the Candida parapsilosis isolate was purified, sequenced, and matched with published sequences of Staphylococcus spp. in GenBank. Results of sequence analysis showed 99\% similarity to Staphylococcus succinus.

Localization of $\boldsymbol{H}$. pylori and Staphylococcus spp. inside the yeast vacuole using direct immunofluorescence assay

Localization of $H$. pylori and Staphylococcus spp. inside the vacuole of $\mathrm{C}$. parapsilosis was performed by direct immunofluorescence (IF) assay. FITC-conjugated IgY-HP prepared against $H$. pylori in hen, ${ }^{31}$ and FITCconjugated IgG-ST prepared against Staphylococcus spp. in rabbit, ${ }^{32}$ were used for detection of $H$. pylori and Staphylococcus spp. inside the yeast's vacuole. IF assay was performed according to Hašek. ${ }^{33} \mathrm{~A}$ fresh culture of yeast in YG $(0.5 \%$ yeast extract and $2 \%$ glucose $)$ broth, was fixed with $7.4 \%$ paraformaldehyde for 120 min while shaking. After washing with $0.1 \mathrm{M}$ potassium phosphate citrate buffer (KCP), fixed cells were permeabilized using lyticase (L4025; Sigma) and Triton X-100. Cells were washed and resuspended in 0.4 M PIPES buffer containing FITC-labeled antibodies and $0.01 \%$ evans blue solution (for color contrast) and incubated at room temperature for $60 \mathrm{~min}$. After washing three times with PIPES, a $10-\mu \mathrm{L}$ volume of yeast suspension was smeared onto a glass slide, air-dried, covered with mounting oil (Invitrogen, USA) and examined by fluorescence microscopy. Fresh cultures of $H$. pylori and Staphylococcus aureus were used as positive controls. A negative control yeast (a yeast with no amplification of H. pylori and Staphylococcus $16 \mathrm{~S}$ rDNA) was used to demonstrate the lack of non-specific interaction of antibodies.

\section{RESULTS}

\section{Isolation of yeasts}

Microscopic examination of gram-stained smears of yeast colonies on YGC agar showed typical yeast morphology. Of 60 samples, 32 (53.3\%) were positive for yeast growth. Yeast-positive samples included 10 of $15(66.6 \%)$ fresh fruits, 8 of $15(53.3 \%)$ dried fruits, 11 of $22(50 \%)$ commercial foods, and 3 out of $8(37.5 \%)$ miscellaneous foods.

\section{Molecular identification of yeasts}

Amplification of the ITS region of 5.8S rDNA from the 32 yeasts revealed bands with a size of 370 to $880 \mathrm{bp}$, which were digested with restriction endonucleases. Yeasts were classified into 13 groups according to their PCR-RFLP pattern. RFLP group 12 with five isolates of C. albicans, group 8 with four isolates of Meyerozyma guilliermondii, group 5 with four isolates of Candida diversa, and group 1 with four isolates of Pichia kudriavzevii contained the highest number of yeast isolates. In the fresh fruits group, isolated yeasts included Zygosaccharomyces bailii $(\times 2)$, $\mathrm{P}$. kudriavzevii $(\times 2)$, Pichia pastoris $(\times 1)$, Zygosaccharomyces mellis $(\times 1)$, Metschnikowia pulcherrima $(\times 1), C$. diversa $(\times 1)$, and Candida catenulata $(\times 2)($ table 1$)$.

In the dried fruits group, isolated yeasts included $P$. kudriavzevii $(\times 1)$, Meyerozyma guilliermondii $(\times 3)$, Saccharomyces cerevisiae $(\times 1)$, C. parapsilosis $(\times 2)$, and Wickerhamomyces anomalus $(\times 1)$ (table 2$)$. In the commercial foods group, isolated yeasts included C. albicans $(\times 3)$, Meyerozyma guilliermondii $(\times 1)$, P. kudriavzevii $(\times 1)$, Saccharomyces cerevisiae $(\times 2)$, C. diversa $(\times 2)$, C. parapsilosis $(\times 1)$, and Yarrowia lipolytica $(\times 1)($ table $3)$. In the miscellaneous foods, isolated yeasts included $C$. albicans $(\times 2)$ and $C$. diversa $(\times 1)($ table 4$)$. 
Table 1: Frequency of Helicobacter pylori 16s rDNA and Staphylococcus 16s rDNA in 10 yeast isolates from fresh fruits

\begin{tabular}{lcccc}
\hline Samples & RFLP group & $\begin{array}{c}\text { Sequencing result } \\
\text { (26S rDNA) }\end{array}$ & $\begin{array}{c}\text { H. pylori- } \\
\text { 16S rDNA }\end{array}$ & $\begin{array}{c}\text { Staphylococci- } \\
\text { 16S rDNA }\end{array}$ \\
\hline Blackberry & 1 & P. kudriavzevii & - & - \\
\hline Strawberry & 2 & Z. bailii & + & - \\
\hline Grape & 3 & Z. mellis & - & - \\
\hline Persimmon & 4 & M. pulcherima & - & - \\
\hline Peach & 2 & Z. bailii & + & - \\
\hline Fig & 5 & C. diversa & + & - \\
\hline Banana & 6 & P. pastoris & + & - \\
\hline White dragon & 7 & C. catenulata & + & - \\
\hline Red dragon & 7 & C. catenulata & + \\
\hline Carrot & 1 & P. kudriavzevii & - \\
\hline
\end{tabular}

Table 2: Frequency of Helicobacter pylori 16s rDNA and Staphylococcus 16s rDNA in eight yeast isolates from dried fruits

\begin{tabular}{lcccc}
\hline Samples & RFLP group & $\begin{array}{c}\text { Sequencing result } \\
\text { (26S rDNA) }\end{array}$ & $\begin{array}{c}\text { H. pylori- } \\
\text { 16S rDNA }\end{array}$ & $\begin{array}{c}\text { Staphylococci- } \\
\text { 16S rDNA }\end{array}$ \\
\hline Date 2 & 1 & P. kudriavzevii & - & - \\
\hline Date 3 & 8 & M. guilliermondii & - & - \\
\hline Date 4 & 9 & S. cerevisiae & + & + \\
\hline Date 5 & 8 & M. guilliermondii & + & + \\
\hline Date 6 & 10 & W. anomalus & + & + \\
\hline Date 7 & 11 & C. parapsilosis & + & + \\
\hline Date 8 & 11 & C. parapsilosis & + & - \\
\hline Heart of palm & 8 & M. guilliermondii & & + \\
\hline
\end{tabular}

Table 3: Frequency of Helicobacter pylori 16s rDNA and Staphylococcus 16s rDNA in 11 yeast isolates from processed and unprocessed commercial foods

\begin{tabular}{lcccc}
\hline Samples & RFLP group & $\begin{array}{c}\text { Sequencing result } \\
\text { (26S rDNA) }\end{array}$ & $\begin{array}{c}\text { H. pylori- } \\
\text { 16S rDNA }\end{array}$ & $\begin{array}{c}\text { Staphylococci- } \\
\text { 16S rDNA }\end{array}$ \\
\hline Brown sugar 1 & 12 & C. albicans & + & - \\
\hline Brown sugar 2 & 12 & C. albicans & + & - \\
\hline Icing sugar & 8 & M. guilliermondii & + & + \\
\hline Quince jam & 1 & P. kudriavzevii & + & - \\
\hline Date syrup & 13 & Y. lipolytica & + & - \\
\hline Sugarcane syrup & 12 & C. albicans & + & - \\
\hline Sugarcane foam & 9 & S. cerevisiae & - & + \\
\hline Cooked beet 1 & 5 & C. diversa & + & - \\
\hline Cooked beet 2 & 11 & C. parapsilosis & + \\
\hline Cooked beet 3 & 5 & C. diversa & + & + \\
\hline Kombucha tea & 9 & S. cerevisiae & + \\
\hline
\end{tabular}

Table 4: Frequency of Helicobacter pylori 16s rDNA and Staphylococcus 16s rDNA in three yeast isolates from miscellaneous samples

\begin{tabular}{lcccc}
\hline Samples & RFLP group & $\begin{array}{c}\text { Sequencing result } \\
\text { (26S rDNA) }\end{array}$ & $\begin{array}{c}\text { H. pylori- } \\
\text { 16S rDNA }\end{array}$ & $\begin{array}{c}\text { Staphylococci- } \\
\text { 16S rDNA }\end{array}$ \\
\hline Pistachio & 5 & C. diversa & + & - \\
\hline Old pickled garlic & 12 & C. albicans & - & - \\
\hline Old pickled garlic syrup & 12 & C. albicans & - & - \\
\hline
\end{tabular}



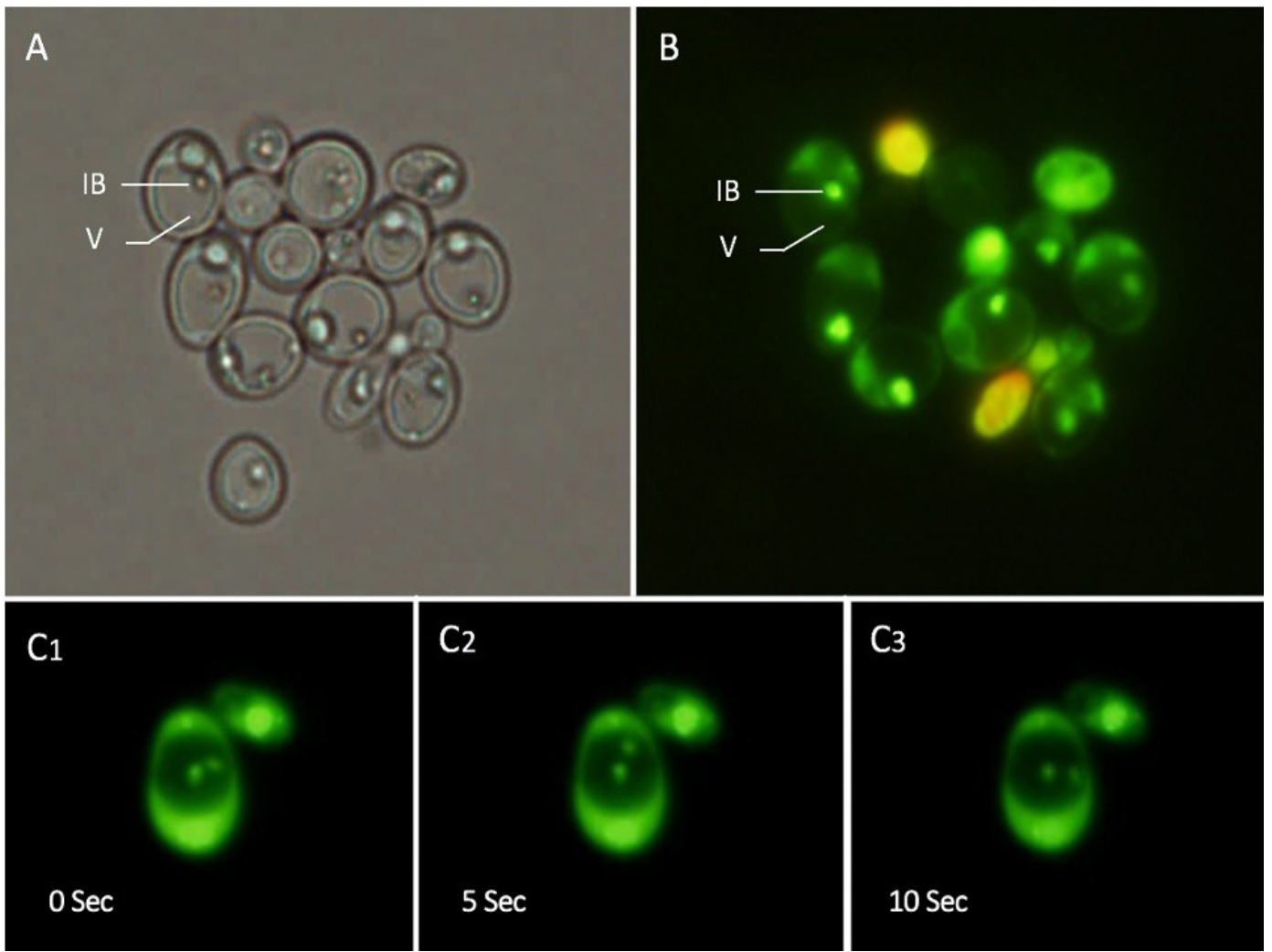

Fig.1: Light and fluorescence microscopy of yeast. A) Light microscopy of yeast cells shows intracellular bacteria (IB) inside yeast's vacuole (V). B) Live intracellular bacteria (IB) appeared as green spots in the vacuole (V) of stained yeast cells. C1-C3) Photographs taken at three-time intervals $(0,5$, and 10 seconds) show the moving bacteria. Original magnification $x 1000$.

\section{Light and fluorescence microscopy of yeast}

Light microscopic examination of wet mounts prepared from cultures of the 32 isolated yeasts showed the occurrence of bacteria inside the vacuole of all the yeast cells (Fig.1 A). Live/Dead staining of yeast cells confirmed the viability of intracellular bacteria (Fig.1 B). Photographs taken from a stained wet mount of yeast, at three-time intervals, showed live and moving bacteria inside the yeast cell vacuole (Fig.1 C1-C3).

Detection of $\mathrm{H}$. pylori- and Staphylococcus-specific 16S rDNA in yeasts

The amplified product of $H$. pylori-specific $16 \mathrm{~S}$ rDNA with a size of $521 \mathrm{bp}$ was detected in 23 of 32 (71.8\%) yeast isolates. The frequency of $H$. pylori-positive yeasts in different groups of samples was determined to be $70 \%$ (7out of 10) in the fresh fruits group: Z. bailii $(\times 2), C$. diversa $(\times 1)$, P. pastoris $(\times 1)$, C. catenulate $(\times 2)$, and P. kudriavzevii $(\times 1)($ table 1$) ; 75 \%$ (6 out of 8$)$ in the dried fruits group: Meyerozyma guilliermondii $(\times 2), C$. parapsilosis $(\times 2)$, W. anomalus $(\times 1)$ and Saccharomyces cerevisiae $(\times 1)$ (table 2$) ; 81.8 \%$ (9 out of 11$)$ in the commercial foods group: C. albicans $(\times 3), P$. kudriavzevii $(\times 1)$, Y. lipolytica $(\times 1)$, Saccharomyces cerevisiae $(\times 2)$, C. diversa $(\times 1)$, and $C$. parapsilosis $(\times 1)$ (table 3 ); and $33.3 \%$ (1 out of 3 ) in miscellaneous foods: $C$. diversa $(\times 1)$ (table 4). Staphylococcus-specific 16S rDNA with a size of $750 \mathrm{bp}$ was detected in $22.2 \%$ (8 out of 36 ) of yeast isolates. The frequency of Staphylococcus spp.positive yeasts was determined to be $62.5 \%$ (5 out of 8 ) in the dried fruits group (Saccharomyces cerevisiae, Meyerozyma guilliermondii, $W$. anomalus, and $2 \times C$. parapsilosis) and 27\% (3 out of 11) in the commercial foods group (Saccharomyces cerevisiae, Meyerozyma guilliermondii and C. diversa) (tables 2 and 3). Yeast isolates from fresh fruits, and miscellaneous foods did not carry Staphylococcus-specific 16S rDNA (tables 1 and 4). The frequency of yeasts containing both $H$. pylori and 

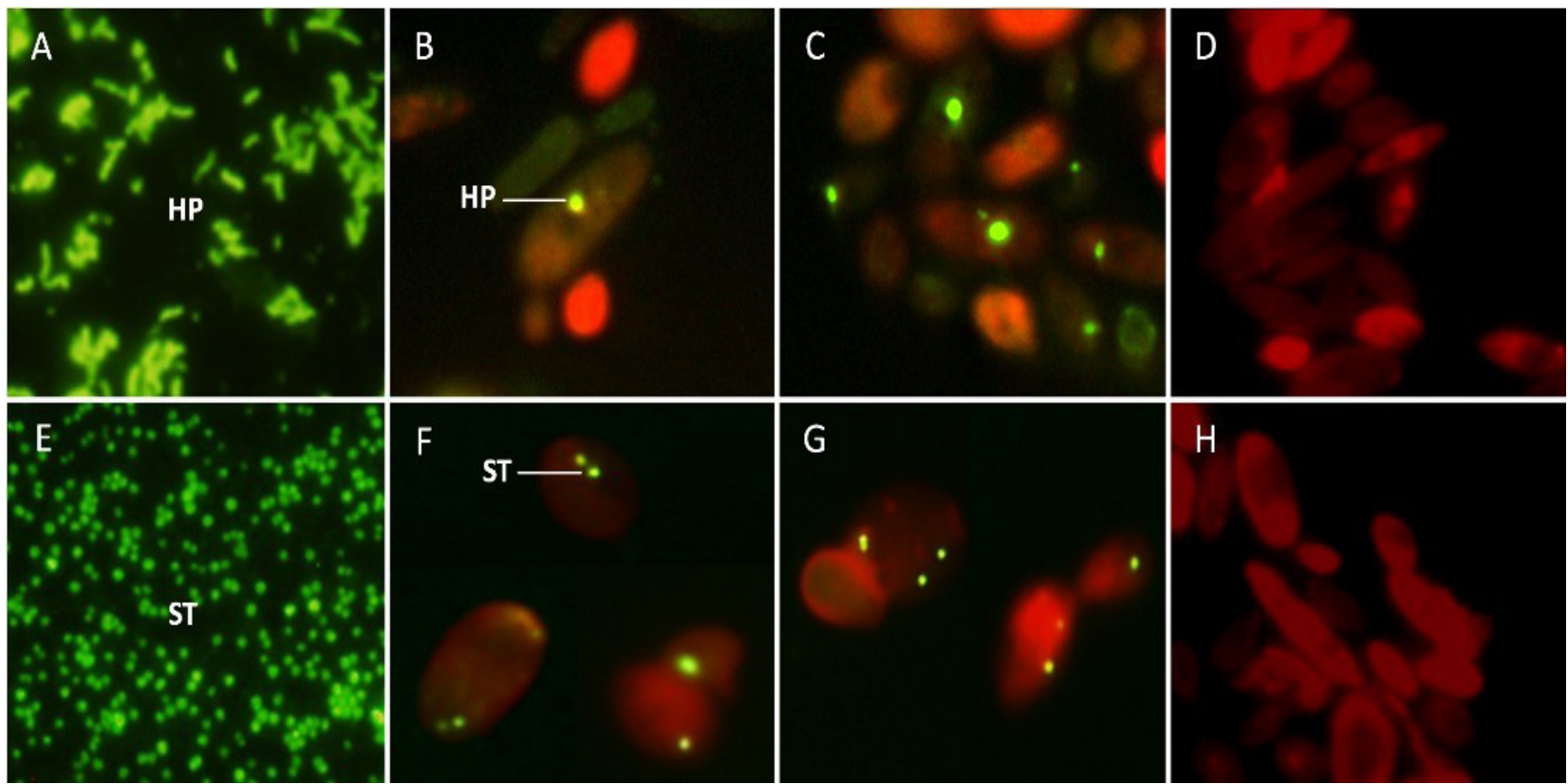

Fig.2: Direct immunofluorescence assay on C. parapsilosis for localization of $\boldsymbol{H}$. pylori and Staphylococcus spp inside the yeast vacuole. Photographs show specific interaction of FITC-labeled IgY-HP with intracellular H. pylori (HP) (B and C) and specific interaction of FITC-labeled IgG-ST with intracellular Staphylococcus (ST) (F and G). Photographs A and $\mathbf{E}$ show positive interaction of labeled antibodies with pure culture of $\mathrm{H}$. pylori and Staphylococci, respectively. Negative control yeast with the dark vacuole, showing the lack of non-specific interaction of antibodies (D and H). Original magnification x 1000 .

Staphylococcus spp. was $62.5 \%$ in dried fruits and $9 \%$ in commercial foods. Altogether, among the 32 isolated yeasts, 17 (53\%) were H. pylori-positive only, two (6\%) were Staphylococcus spp.-positive only, six (18.7\%) were positive for both $H$. pylori and Staphylococcus spp., and seven $(21.8 \%)$ were negative for both.

\section{Localization of $\boldsymbol{H}$. pylori and Staphylococcus spp.} inside the yeast vacuole using direct immunofluorescence assay

Specific interaction of FITC-IgY-HP (Fig.2, B and C) or FITC-IgG-ST (Fig.2, F and G) with intracellular bacteria confirmed the identity of bacteria as $H$. pylori or Staphylococcus spp. and their localization inside yeast's vacuole. Dark vacuole of negative control yeast without fluorescent spots indicated the lack of non-specific interaction of antibodies (Fig.2, D and H).

\section{DISCUSSION}

Carbohydrates are the most popular foods consumed by humans worldwide. In addition to be a major carbon source for building living cells, their sweet taste, and energy provi- sion afford these compounds a very special place in the human diet. Sweet foods are recognized as comfort foods because their consumption leads to elevation of serotonin, the known anti-depressant neurotransmitter that reduces pain and regulates sleep and the biological clock. ${ }^{34}$ Sugars are also used to improve the quality of foods due to their functional properties. ${ }^{35}$ Furthermore, sugar and salt are the oldest preservatives that, when added to food materials, protect them against microbial spoilage by producing high osmotic pressure. Accordingly, sugars are frequently added to a variety of foods and beverages. Bacteria cannot withstand the osmotic stress of sugar-rich environments and die, while osmotolerant yeasts survive and even multiply. ${ }^{36}$

Fresh and dried fruits, fruit juice, and refined sugar products are sugar-rich environments of plant origin that cause stress to microbial cells by reducing water activity, changing cell turgor pressure, and destabilizing macromolecules. ${ }^{15}$ This might indicate that floral nectar and fruits have evolved to accumulate high concentrations of sugar to protect the fertile parts of plants from microbial attack. ${ }^{37,38}$ However, osmotolerant yeasts that show max- 
imum fitness in high concentrations of sugars, ${ }^{39}$ increase their population and become established as the normal microflora of such sugar-rich plant environments, including floral nectar and fruits. ${ }^{40}$ These symbiotic yeasts, while feeding on plants, stimulate plant metabolism, and inhibit phytopathogens. ${ }^{41,42}$ Insects, which play an important role in pollination and reproduction of plants, feed on yeasts and carry them from the soil to plants and disperse them within plants during pollination. ${ }^{43}$ It appears that symbiosis of yeasts with insects and plants is an important and inevitable evolutionary event. ${ }^{44}$ Accordingly, yeasts as permanent associates of plants, enter the human digestive system through the consumption of sugar-rich and plantderived food products.

Yeasts with high potential for genotypic ${ }^{45,46}$ and phenotypic ${ }^{47}$ plasticity are permanent symbiotic inhabitants of plants, ${ }^{41,42}$ insects, ${ }^{48}$ animals, ${ }^{49}$ and humans ${ }^{50}$ in a wide range of environments. ${ }^{37,51}$ Accordingly, it is not surprising that fungi with these sophisticated properties have evolved to serve as a unique niche for sheltering the endosymbiotic bacteria. ${ }^{52}$ In our previous studies, H. pylori-specific genes were detected in oral, ${ }^{53}$ gastric, ${ }^{54}$ vaginal, ${ }^{55}$ and foodborne 7 yeasts. Furthermore, $H$. pylori-specific proteins were detected in the protein pool of gastric yeasts by western blot technique, ${ }^{56}$ and intracellular H. pylori was localized in the vacuole of Candida yeast by FITC-IgY-HP. ${ }^{31}$ Results of similar studies performed in our lab showed the detection of Staphylococcus- specific genes ${ }^{57}$ and proteins ${ }^{32}$ in gastric yeasts as well as staphylococcal localization inside the vacuole of gastric yeast by immunodetection and FISH methods. ${ }^{32}$ It was proposed that inside the vacuole of Candida yeast, H. pylori, or Staphylococcus are protected from environmental stresses and provided with nutrients for survival and multiplication. Accordingly, yeast was suggested as a potent reservoir of $H$. pylori and Staphylococcus. ${ }^{7,53,54,58}$

Among the 32 yeasts isolated in this study, 17 (53\%) were $H$. pylori-positive only, two $(6 \%)$ were Staphylococcus spp.-positive only, six (18.7\%) were positive for both H. pylori and Staphylococcus spp., and seven (21.8\%) were negative for both bacteria. Among the sugarrich foods studied, dates showed the greatest potential for supporting intracellular H. pylori (75\%) and Staphylo- coccus spp. $(62.5 \%)$, or both $(62.5 \%)$ in yeasts.

The frequency of $H$. pylori-positive yeasts in fresh fruits, dried fruits, and commercial foods was 70-81.8\%. Fresh fruits contain high levels of sugars, other nutrients, and intermediate water activity that favor microbial growth. However, acidic $\mathrm{pH}$ eliminates bacteria and provides appropriate conditions for fungal growth. The natural microbiota of fruits is commonly composed of yeasts such as Candida, Pichia, Saccharomyces, Hanseniaspora, and Zygosaccharomyces. ${ }^{21}$ Dried fruits such as date fruits, in addition to sugar, contain salts and minerals, fatty acids, amino acids, proteins, and vitamins, including B1, B2, and B3. Furthermore, dates are rich in different kinds of sterols ${ }^{59,60}$ that are precursors of ergosterol involved in the synthesis of yeast membranes. ${ }^{61}$ It is noteworthy that sterols also serve as precursors of cholesterol, an important constituent of $H$. pylori cell membrane. ${ }^{62}$ Commercial foods such as sugar cubes, granulated white and brown sugars, and other related high-sugar products are frequently used as sweet additives to tea, coffee, and sherbets or to formulated foods such as desserts and pastries. These compounds with high sugar content could carry yeasts either of plant origin or introduced as post-operation contaminants. ${ }^{63}$

Among the miscellaneous foods investigated, the two C. albicans isolates from old pickled garlic, and old pickled garlic syrup did not contain H. pylori or Staphylococcus spp. However, the three C. albicans isolates from commercial foods, and eight out of nine Candida spp. from other foods carried H. pylori. This might indicate that long storage of pickled garlic in vinegar, although favoring the survival of $C$. albicans yeasts, could exert a negative effect on the survival of intracellular bacteria, leading to a reduction in bacterial copy number such that bacterial DNA was not detectable by PCR. Negative PCR results have been suggested to result from failure in the detection of bacterial genes due to low bacterial copy number, inadequate amount of extracted DNA, ${ }^{64}$ or lack of primer recognition sites in bacterial DNA due to variation in the target sequence. ${ }^{65}$

Results of this study showed that sugar-rich foods, whether naturally sweet or containing added sugar, are carriers of osmotolerant yeasts that could contain $H$. pylori 
and/or Staphylococcus spp. Detection of H. pylori- and/ or Staphylococcus-specific genes shows the probable occurrence of multiple endosymbiotic bacteria in the vacuoles of yeasts with different frequencies. Microscopic observations of bacteria in new generations of yeasts along with amplification of $H$. pylori- and Staphylococcusspecific genes from consecutive generations indicate that new yeast cells can inherit the intracellular bacteria as part of their vacuolar content. Extensive studies on the intracellular existence of non-culturable bacteria inside arbuscular mycorrhizal fungi indicated that the fungal vacuole provided a nourishing and protective niche for the endosymbiotic bacterium 'Candidatus Glomeribacter gigasporarum' ( $\mathrm{CaGg}$ ), facilitating its replication and transmission to the next generation. ${ }^{52}$ Moreover, the occurrence of two types of endosymbiotic bacteria has been reported in arbuscular mycorrhizal fungi: the gramnegative beta proteobacterium $\mathrm{CaGg}$, and a gram-positive molicutes-related endobacterium. ${ }^{66}$ It is noteworthy that microscopic observation of bacterial structures inside the vacuoles of yeast isolates with negative results for amplification of $H$. pylori or Staphylococcus genes suggests the likelihood of the occurrence of other intracellular bacteria yet to be identified.

Yeasts enter the food cycle of animals, including humans, through the consumption of sugar-rich and plant-derived foods. Yeasts are able to survive in the human gastrointestinal tract due to their high potential to adapt to different stressful conditions and return to natural soils when excreted. It can be concluded that different yeasts that occur in the soil are more or less representatives of the yeast populations of plant and animal life above the soil surface. In this fashion, yeasts establish more or less similar populations in soils, plants, and animals, including humans. In all the steps of the food cycle, yeast may carry its intracellular bacteria and spread it to different hosts such as insects, plants, and animals. Accordingly, the intracellular occurrence of H. pylori, Staphylococcus spp. and probably other bacteria inside the yeast could be regarded as a sophisticated survival strategy of bacteria that evolved along the evolutionary path. Overall, yeasts may be regarded as permanent reservoirs of bacteria, and thus bacteria will exist as long as yeasts persist.

\section{ETHICAL APPROVAI}

There is nothing to be declared.

\section{CONFLICT OF INTEREST}

The authors declare no conflict of interest related to this work.

\section{REFERENCES}

1. Kusters JG, van Vliet AH, Kuipers EJ. Pathogenesis of Helicobacter pylori infection. Clin Microbiol Rev 2006;19:449-90. doi: 10.1128/CMR.00054-05.

2. Weyermann M, Rothenbacher D, Brenner H. Acquisition of Helicobacter pylori infection in early childhood: independent contributions of infected mothers, fathers, and siblings. Am J Gastroenterol 2009;104:182-9.

3. Thomas E, Jiang C, Chi D, Li C, Ferguson Jr D. The role of the oral cavity in Helicobacter pylori infection. Am J Gastroenterol 1997;92:2148-54.

4. Poms RE, Tatini SR. Survival of Helicobacter pylori in ready-to-eat foods at $4 \mathrm{C}$. Int $J$ Food Microbiol 2001;63:281-6. doi: 10.1016/s0168-1605(00)00441-4.

5. Hegarty J, Dowd M, Baker K. Occurrence of Helicobacter pylori in surface water in the United States. J Appl Microbiol 1999;87:697-701. doi: 10.1046/j.13652672.1999.00912.x

6. Wesley IV. Helicobacter and Arcobacter species: risks for foods and beverages. J Food Prot 1996;59:112732. doi: 10.4315/0362-028X-59.10.1127.

7. Salmanian AH, Siavoshi F, Beyrami Z, LatifiNavid S, Tavakolian A, Sadjadi A. Foodborne yeasts serve as reservoirs of Helicobacter pylori. $J$ Food Safety 2012;32:152-60. doi: 10.1111/j.17454565.2011.00362.x

8. Marino M, Frigo F, Bartolomeoli I, Maifreni M. Safetyrelated properties of staphylococci isolated from food and food environments. J Appl Microbiol 2011;110:55061. doi: 10.1111/j.1365-2672.2010.04909.x

9. Lin YJ, Alsad L, Vogel F, Koppar S, Nevarez L, Auguste $\mathrm{F}$, et al. Interactions between Candida albicans and Staphylococcus aureus within mixed species biofilms. Bios 2013;84:30-9. doi: 10.1893/0005-3155-84.1.30.

10. Allison DL, Willems H, Jayatilake J, Bruno VM, Peters BM, Shirtliff ME. Candida-Bacteria Interactions: Their Impact on Human Disease. Microbiol Spectr 2016;4. doi: 10.1128/microbiolspec.VMBF-0030-2016

11. Hohmann S. Osmotic stress signaling and osmoadapta- 
tion in yeasts. Microbiol Mol Biol Rev 2002;66:30072. doi: $10.1128 / \mathrm{mmbr} \cdot 66.2 .300-372.2002$.

12. Charoenchai C, Fleet G, Henschke P, Todd B. Screening of non-Saccharomyces wine yeasts for the presence of extracellular hydrolytic enzymes. Australian J Grape Wine Res 1997;3:2-8. doi: 10.1111/j.17550238.1997.tb00109.x

13. Strauss M, Jolly N, Lambrechts M, Van Rensburg P. Screening for the production of extracellular hydrolytic enzymes by non-Saccharomyces wine yeasts. $J$ Appl Microbiol 2001;91:182-90. doi: 10.1046/j.13652672.2001.01379.x

14. Deak T. Handbook of food spoilage yeasts. $C R C$ press; 2007.

15. Lievens B, Hallsworth JE, Pozo MI, Belgacem ZB, Stevenson A, Willems KA, et al. Microbiology of sugarrich environments: diversity, ecology and system constraints. Environ Microbiol 2015;17:278-98. doi: 10.1111/1462-2920.12570.

16. Brown A. Microbial water stress. Bacteriol Rev 1976;40:803-46.

17. Schobert B. Is there an osmotic regulatory mechanism in algae and higher plants? J Theor Biol 1977;68:1726. doi: 10.1016/0022-5193(77)90224-7.

18. Thomé PE. Cell wall involvement in the glycerol response to high osmolarity in the halotolerant yeast Debaryomyces hansenii. Antonie van Leeuwenhoek 2007;91:229-35. doi: 10.1007/s10482-006-9112-8.

19. Tokuoka K. Sugar and salt tolerant yeasts. J Appl Microbiol 1993;74:101-10. doi: 10.1111/j.1365-2672.1993.tb03002.x

20. Ragaert P, Devlieghere F, Loos S, Dewulf J, Van Langenhove $\mathrm{H}$, Foubert I, et al. Role of yeast proliferation in the quality degradation of strawberries during refrigerated storage. Int J Food Microbiol 2006;108:4250. doi: 10.1016/j.ijfoodmicro.2005.10.017.

21. Tournas V, Katsoudas E. Mould and yeast flora in fresh berries, grapes and citrus fruits. Int J Food Microbiol 2005;105:11-7. doi: 10.1016/j.ijfoodmicro.2005.05.002.

22. Rose AH, Harrison JS. The yeasts. Vol 2: Yeasts and the environment. 1987.

23. Tilbury R. Studies on the microbiological deterioration of raw cane sugar. Diss, M.Sc. Thesis, University of Bristol, Bristol, UK; 1967.

24. Chou CC. Handbook of sugar refining: a manual for the design and operation of sugar refining facilities. Vol 467: John Wiley \& Sons; 2000.
25. Green MR, Sambrook JJCSHP. Rapid isolation of yeast DNA. Cold Spring Harb Protoc 2018;2018. doi: 10.1101/pdb.prot093542.

26. Esteve-Zarzoso B, Belloch C, Uruburu F, Querol A. Identification of yeasts by RFLP analysis of the $5.8 \mathrm{~S}$ rRNA gene and the two ribosomal internal transcribed spacers. Int J Syst Bacteriol 1999;49:329-37. doi: 10.1099/00207713-49-1-329.

27. Carvalho C, Meirinho S, Estevinho M, Choupina A. Yeast species associated with honey: different identification methods. Arch Zootec 2010;59:103-13.

28. Lu Y, Redlinger TE, Avitia R, Galindo A, Goodman K. Isolation and genotyping of Helicobacter pylori from untreated municipal wastewater. Appl Environ Microbiol 2002;68:1436-9. doi: 10.1128/aem.68.3.1436-1439.2002.

29. Zhang K, Sparling J, Chow BL, Elsayed S, Hussain Z, Church DL, et al. New quadriplex PCR assay for detection of methicillin and mupirocin resistance and simultaneous discrimination of Staphylococcus aureus from coagulase-negative staphylococci. J Clin Microbiol 2004;42:4947-55. doi: 10.1128/JCM.42.11.49474955.2004 .

30. Jaffe RI, Lane JD, Albury SV, Niemeyer DM. Rapid extraction from and direct identification in clinical samples of methicillin-resistant staphylococci using the PCR. J Clin Microbiol 2000;38:3407-12.

31. Saniee P, Siavoshi F, Nikbakht BG, Khormali M, Sarrafnejad A, Malekzadeh R. Localization of H. pylori within the vacuole of Candida yeast by direct immunofluorescence technique. Arch Iran Med 2013;16:705-10.

32. Tavakolian A, Heydari S, Siavoshi F, Nikbakht Brojenic GR, Sarrafnejad A, Eftekhar F, et al. Localization of Staphylococcus inside the vacuole of Candida albicans by immunodetection and FISH. Infect Genet Evol 2019;75:104014. doi: 10.1016/j.meegid.2019.104014.

33. Hašek J. Yeast fluorescence microscopy. Methods Mol Biol 2006:85-96. doi: 10.1385/1-59259-958-3:085.

34. Fortuna JL. Sweet preference, sugar addiction and the familial history of alcohol dependence: shared neural pathways and genes. JPsychoactive Drugs 2010;42:14751. doi: 10.1080/02791072.2010.10400687.

35. Davis EA. Functionality of sugars: physicochemical interactions in foods. Am J Clin Nutr 1995;62:170-7. doi: 10.1093/ajen/62.1.170S.

36. Morris SA. Food and package engineering. John Wiley \& Sons; 2011. 
37. Carter D, Liti G, Moses A, Warringer J, Parts L, James $\mathrm{S}$, et al. Population genomics of domestic and wild yeasts. Nature 2009. doi: 10.1038/nature07743.

38. Williams JP, Hallsworth JE. Limits of life in hostile environments: no barriers to biosphere function? Environ Microbiol 2009;11:3292-308. doi: 10.1111/j.14622920.2009.02079.x

39. Mora D, Arioli S, Compagno C. Food environments select microorganisms based on selfish energetic behavior. Front Microbiol 2013;4. doi: 10.3389/fmicb.2013.00348.

40. Pozo MI, Lachance M-A, Herrera CM. Nectar yeasts of two southern Spanish plants: the roles of immigration and physiological traits in community assembly. FEMS Microbiol Ecol 2012;80:281-293. doi: 10.1111/j.15746941.2011.01286.x

41. Lachance MA, Walker GM. Yeasts. eLS 2001; pp.1-13.

42. Glushakova A, Chernov IY. Seasonal dynamic of the numbers of epiphytic yeasts. Microbiologiia 2007;76:590-5.

43. Gonzalez F. Symbiosis between yeasts and insects. Crop Production Science 2014;3

44. Witzgall P, Proffit M, Rozpedowska E, Becher PG, Andreadis S, Coracini M, et al. "This is not an apple"-yeast mutualism in codling moth. $J$ Chem Ecol 2012;38:94957. doi: 10.1007/s10886-012-0158-y.

45. Herrera C, Pozo M, Bazaga P. Clonality, genetic diversity and support for the diversifying selection hypothesis in natural populations of a flower-living yeast. Mol Ecol 2011;20:4395407. doi: 10.1111/j.1365-294X.2011.05217.x

46. Herrera CM. Population growth of the floricolous yeast Metschnikowia reukaufii: effects of nectar host, yeast genotype, and host $\times$ genotype interaction. FEMS Microbiol Ecol 2014;88:250-7. doi: 10.1111/1574-6941.12284.

47. Sultan SE, Spencer HG. Metapopulation structure favors plasticity over local adaptation. Am Nat 2002;160:271283. doi: $10.1086 / 341015$.

48. Vega FE, Dowd PF. The role of yeasts as insect endosymbionts. Insect-Fungal Associations: Ecology and Evolution. Oxford University Press, New York 2005:211-243.

49. Nichita I, Marcu A. The fungal microbiota isolated from cats and dogs. Scientific Papers Animal Science and Biotechnologies 2010;43:411-4.

50. Soll DR, Galask R, Schmid J, Hanna C, Mac K, Morrow B. Genetic dissimilarity of commensal strains of Candida spp. carried in different anatomical locations of the same healthy women. J Clin Microbiol 1991;29:1702-10.
51. Angebault C, Djossou F, Abélanet S, Permal E, Soltana $\mathrm{MB}$, Diancourt L, et al. Candida albicans is not always the preferential yeast colonizing humans: a study in Wayampi Amerindians. J Infect Dis 2013;208:170516. doi: 10.1093/infdis/jit389.

52. Bianciotto V, Genre A, Jargeat P, Lumini E, Becard G, Bonfante P. Vertical transmission of endobacteria in the arbuscular mycorrhizal fungus Gigaspora margarita through generation of vegetative spores. Appl Environ Microbiol 2004;70:3600-8. doi: 10.1128/AEM.70.6.36003608.2004 .

53. Siavoshi F, Salmanian AH, Kbari FA, Malekzadeh R, Massarrat S. Detection of Helicobacter pylori-Specific Genes in the Oral Yeast. Helicobacter 2005;10:318-22. doi: 10.1111/j.1523-5378.2005.00319.x

54. Siavoshi F, NouraliAhari F, Zeinali S, HashemiDogahed M, Malekzadeh R, Massarrat S. Yeast protects Helicobacter Pylori against the environmental stress. Arch Iran Med 1998;1:2-8.

55. Siavoshi F, Taghikhani A, Malekzadeh R, Sarrafnejad A, Kashanian M, Jamal AS, et al. The role of mother's oral and vaginal yeasts in transmission of Helicobacter pylori to neonates. Arch Iran Med 2013;16:288.

56. Saniee P, Siavoshi F, Nikbakht BG, Khormali M, Sarrafnejad A, Malekzadeh R. Immunodetection of Helicobacter pylori-specific proteins in oral and gastric Candida yeasts. Arch Iran Med 2013;16:624-30.

57. Tavakolian A, Siavoshi F, Eftekhar F. Candida albicans Release Intracellular Bacteria When Treated With Amphotericin B. Arch Iran Med 2018;21:191-8.

58. Siavoshi F, Saniee P. Vacuoles of Candida yeast as a specialized niche for Helicobacter pylori. World $J$ Gastroenterol 2014;20:5263. doi: 10.3748/wjg.v20. i1 8.5263 .

59. Al-Shahib W, Marshall RJ. The fruit of the date palm: its possible use as the best food for the future? Int J Food Sci Nutr 2003;54:247-59. doi: 10.1080/09637480120091982

60. Kikuchi N, Miki T. The separation of date (Phoenix dactylifera) sterols by liquid chromatography. Microchimica Acta 1978;69:89-96.

61. Noda H, Koizumi Y. Sterol biosynthesis by symbiotes: cytochrome P450 sterol C-22 desaturase genes from yeastlike symbiotes of rice planthoppers and anobiid beetles. Insect Biochem Mol Biol 2003;33:649-58. doi: 10.1016/s0965-1748(03)00056-0.

62. Haque M, Hirai Y, Yokota K, Mori N, Jahan I, Ito H, et al. Lipid profile of Helicobacter spp.: presence of 
cholesteryl glucoside as a characteristic feature. $J$ Bacteriol 1996;178:2065-70. doi: 10.1128/jb.178.7.20652070.1996.

63. ICMSF. Sugar, syrups and honey. Micro-Organisms in Foods: Microbial Ecology Food Commodities 1998:418-39. doi: 10.1007/978-1-4615-5307-12.

64. Whelen AC, Persing DH. The role of nucleic acid amplification and detection in the clinical microbiology laboratory. Annu Rev Microbiol 1996;50:349-73. doi: 10.1146/annurev.micro.50.1.349.

65. Whiley D, Lambert S, Bialasiewicz S, Goire N, Nissen M, Sloots T. False-negative results in nucleic acid amplification tests-do we need to routinely use two genetic targets in all assays to overcome problems caused by sequence variation? Crit Rev Microbiol 2008;34:71-6. doi: 10.1080/10408410801960913.

66. Desiro A, Salvioli A, Ngonkeu EL, Mondo SJ, Epis S, Faccio A, et al. Detection of a novel intracellular microbiome hosted in arbuscular mycorrhizal fungi. ISME 2014;8:257-70. doi: 10.1038/ismej.2013.151. 